\title{
OPTIMIZATION OF WORKPLACE DESIGN FOR PEOPLE WITH ALTERNATIVE ABILITIES
}

\section{Ewa GÓRSKA}

Faculty of Management

Warsaw University of Technology, 02-524 Warszawa, Poland

E.Gorska@wz.pw.edu.pl

\begin{abstract}
An employer who wants to employ a person with alternative disturbances faces a difficult problem of selecting a workstation and tasks suitable to a given person's disease since even the same case of disease does not guarantee identical organizational solutions of a workstation. However the more complex the movement disfunction, the more difficult the task is. At the same time it is important that work results of a workstation allow achieving complex productivity. The article presents an attempt at elaborating a method aided by a computer system which allows introducing changes or modifications of workstation space, place equipment and facilities or installing additional elements enabling effective and productive work performance by a person with precisely defined abilities. Presented results of piloting researches have proven that the elaborated method of aiding decisions while adapting workstations to needs and abilities of people with movement disfunction will bring social and economic benefits.
\end{abstract}

Key words: abilities of disabled people, workstation design, computer support, workstation requirements.

\section{1}

\section{Introduction}

According to the regulations currently in force, each enterprise must be prepared to employ people with alternative abilities with different types of disabilities. Fulfilling this criterion requires the introduction of socalled "integration solutions" in all areas of the company's working environment (technical, economic and social areas).

They consist of:

- adapting buildings and rooms to the needs of people with alternative abilities by abolishing architectural barriers, which make it very difficult for people with alternative abilities to move around,

- elaborating procedures, which, in a systematic way will enable to adapt each workstation to the candidate with a particular impairment,

- creating participation and equal chances mechanisms leading to work satisfaction which will eventually lead to self realization and personal development,

- linking work motivation with the motivation to earn money so that in result work could lead to fulfillment of needs and encouragement of more effective work.

Working conditions created in this way should guarantee substantial benefits for the company as they provide opportunities for people with alternative abilities, facilitate achieving high working efficiency and help gain working satisfaction. Inasmuch as there are a lot of companies in Poland, which can pride themselves for having good architectural solutions, adaptation of workstations to disabled people's needs still creates a lot of problems.

As a result of researches a special method which aids decision taking process when designing workstations for people with alternative abilities and in particular with alternative disfunction, has been elaborated (this research was supported by a grant from the National Science Committee No 705316 supervised by Ewa Górska).

Proper researches were preceded by piloting researches to examine the scale of the problem, its complexity and to estimate potential costs of elaborating and implementing the method. For the piloting researches a test sample was chosen consisting of 100 workstations which function in small and medium companies of work protection, and 100 cases of movement diseases in patients who are registered in companies' medical and rehabilitation clinics.

\section{Problem statement}

Legal regulations, both in the country and worldwide, oblige employers to create new workplaces for people with alternative abilities. However, they do not specify how to proceed with this serious problem in order to make people with alternative abilities use the oppor- 
tunity and take the employers' job offer. Hence in many scientific centers there are new initiatives and actions being taken at the moment in hope to increase chances for employment of the disabled. This is done by learning about needs and potentialities of people with alternative abilities [1, 2, 9, 10 - 13], developing methods which allow work and workstation analysis $[4,16,17]$ and introducing methods which concern adaptation of workstation to the limited abilities of people with alternative abilities [15].

Despite so many attempts there is no efficient tool allowing effective and precise adaptation of workstation to needs and abilities of disabled people. It is the result of both great variety of disfunctions and workstations. Recruiting an employee for a definite position can take place in the course of adapting a workstation to an employee or selecting a suitable workstation to abilities of a disabled person. Depending on the characteristic tasks for a workstation and spatial parameters, these factors can be defined as conditions of first and second rank.

Conditions of lower rank are those which can be corrected without change of a functional destination of a given workstation, and they include e.g. limitations of movement space, improper geometrical parameters of working place, communication routes, etc. These are re-definable parameters that can be corrected within an existing workstation. They are applicable when an employee with disfunctions is highly required at a given workstation due to his particular skills, either manual or intellectual and disturbances of lower rank do not allow in normal conditions to employ a disabled person for the realization of these tasks.

However, parameters of higher rank are those that cannot be corrected without change of functional destination of a given workstation e.g. technology. In case of non-adaptable workstations it is assumed that a workstation among tasks for which it is created cannot be modified at all. In these cases a given workstation should be matched to persons who despite their disfunctions will not have difficulties in performing their assigned tasks.

Amongst many areas, which require close analysis, this research focuses on the issue of the spatial design of workstation. First of all, it is a question of designing workstations in accordance with the needs of people with alternative abilities, and in particular with limb impairment.
Physical adaptation of workstations can be resolved into introducing changes or modifications which consist in establishing adequate measure proportions of workstations, adequate arrangement of equipment, installing additional elements or removing those which hinder performance of some given professional activities. If need be, an employer should provide a disabled employee with rehabilitation equipment which is adapted to the type of disability and which enables successful performance of professional activities.

It has been assumed that in order to choose a good workplace for a person with alternative abilities it is necessary to:

- perform complex analysis and evaluation of a person with alternative abilities paying special attention to his natural skills and abilities, and not disabilities,

- perform analysis of work and workstations requirements,

- compare the results of both analyses and define relations between skills and abilities of a person with alternative abilities on the one hand and workstation requirements on the other and on the basis of both generate an adequate workplace for a given person,

- design a workstation in such a way so that it gives a disabled employee independence and autonomy, what is more a workstation should be universal enough for a healthy person (workstation should not be recognized as designed especially for a disabled person),

- elaborate a computer program aiding decisions in conditions when there are two sets of elements' features cooperating in definite situations. These cooperating modeled teams are: an employee endowed with perception-alternative dysfunctions and a spatial structure of workstation which is adaptable to his abilities and needs.

\section{Industrial context}

Elaborating method of designing spatial structure of workstations for persons with alternative dysfunctions required creating a database about workstations and possible cases of limb diseases. For the sake of the method two questionnaires have been prepared: the first one has been devoted to registration of requirements posed by work and geometry parameters of a workstation according to identified modules, the second one is devoted to a detailed description of disa- 
bilities resulting from the type of disease, including among others data about the type of disfunction, the range of perception-alternative limitations, preferences concerning potential work.

From the point of view of the aim of conducted researches the companies of work protection and medical-rehabilitation clinics were recognized as the most representative companies and therefore the questionnaires were sent to them. The questionnaire which describes a disabled person was sent to 25 clinics in 16 voivodships. After 3 months 100 questionnaires were sent back from 13 clinics describing from 5 to 10 types of limb diseases. The researches included a group of patients whose limb dysfunctions did not disqualify a person to start a normal job. 96 out of 100 questionnaires were sent back and filled in correctly.

Questionnaires on workstation requirements were addressed to 25 companies of work protection in 13 cities. Besides big metropolis (Warsaw, Łódź, Poznań) the research covered smaller cities (Radom, Siedlce, Kozienice, Kobyłka near Warsaw, Orońsk near Radom). All the questionnaires describing 100 workstations were filled in correctly.

\section{$4 \quad$ Results of piloting researches}

Due to complexity and variety of the discussed problem, elaboration of the method of designing workstations for the disabled people was preceded by piloting researches. The scope of piloting researches was to identify conditions which were important for good adaptation of workstation to a disabled person, systematize job market offers for people with limb dysfunction and identify prevailing limb dysfunctions. There are two methods which were used in piloting researches:

- clinical exploration including a detailed analysis of a particular group of disabled people and worstations; the advantage of such researches is depth of analyses and possibility of formulating hypotheses on the basis of obtained results which can be verified in researches on large samples; their disadvantage is low representation of the researches' results which is caused by minimal research sample [6],

- large sample studies consist in analyzing big groups of workstations and disabled people; used information comes from survey reports, statistical database, questionnaire researches; the advantage is a high credibility of results allowing generalizations which concern bigger population; the disadvantage is narrowing the number of analyzed problems [6].

Information used to analysis and evaluation of present state of affairs is the result of current regulations, scientific publications, statistical data, summaries of work conditions inspections, experience of companies and private questionnaire researches in the companies of work protection and rehabilitation clinics located in the company.

Results of piloting researches allowed to settle:

- significance of the problem,

- permanence of the problem in time from the legal perspective,

- scale and structure of the problem,

- complexity of the problem.

In order to settle the above conditions and collect data necessary for the elaboration of the prototype of the method and verification of the method on the representative statistical sample, piloting researches have been carefully designed and carried out.

\subsection{Significance of the problem}

The degree of adaptation of the company to the needs of disabled people is decided by National Work Inspection (in Polish: PIP). Unfortunately, in reference to the selection of workstations for given dysfunctions, there are no recommendations or contraindications.

The inspection, carried out by PIP in the first six months of 2007 inspected 2437 companies of work protection (13\% of total amount), which employed about 373.800 disabled people and discovered the following [14]:

- not all objects met the requirements of work safety regulations $(43 \%)$,

- workstations were organized without observing the requirements of acts on surface and height of rooms $(35 \%)$,

- machines and equipment which were operated by disabled people did not always have tools adapted to different types of employees' diseases (41\%),

- there were architectural barriers which hindered movement in working places, on the roads and communication routes $(20 \%)$.

Companies of different profile of activity and, in particular, production, commercial, development and transportation companies were controlled. The conclusion was evident: despite many shortcomings high 
unemployment among people with alternative abilities make them accept bad working conditions. A fear of losing opportunity for an active life and sense of stability, which work provides, forces disabled people to look for job by at any cost.

\subsection{Permanence of the problem in time from the legal perspective}

The increasing problem of disability brings about the situation when countries and different international organizations start special actions and activities for disabled people, also meant to prevent disabilities. In result the question of providing communication opportunities and access of workstations to disabled people with limb alternative dysfunction is a great social and economic problem.

\subsubsection{Social aspect}

An urgent need to provide people with alternative abilities with accessible workstations has found its solution in the following legal acts:

- on 1st August 1997 The Charter of Rights of People with Alternative Abilities was adopted (M.P No. 50, position 474), in which The Parliament of Poland recognized that people with alternative abilities have right to independent, autonomous and active life and they may not be the object of discrimination,

- Labour Code article. $237 \S 1$ and Resolution of Ministry of Labour and Social Policy from 26 September 1997 on general regulations of work safety (Dz.U. No. 129, position 844 with later amendments), saying that: An employer who employs disabled people should guarantee adaptation of workstations and easy access to workstation to needs and limited abilities of disabled employers (§ 48),

- Regulation of Ministry from 29 January 2007 on help for employers who employ people with alternative abilities (Dz.U. from 2007 No. 20, position 118),

- law from 7th July 1994 - Building law (Dz.U. No. 89 , position 414, with later amendments),

- regulation issued by the Ministry of Infrastructure from 12th April 2002 concerning technical conditions which should be fulfilled in public buildings and their location (Dz.U. from 2002 No. 75, position 690),

- law from 27th August 1997 concerning professional and social rehabilitation and employment of people with alternative abilities (Dz.U. No. 123, position 776 , with later amendments).

\subsubsection{Economic aspect}

In practice an employer who wants to employ a person with alternative abilities, faces a difficult task of finding an adequate job and tasks for the given person with movement problems. The more difficult is the task, the more complex is the movement impairment. What is more an employer does not have at his disposal solution patterns which could aid him to make right decisions in this matter: how to maintain productivity of the job position while employing people with alternative abilities. Estimated figures concerning decreased efficiency of the work of people with alternative abilities according to the type of disability have been presented in Table 1.

Decrease in productivity results not only from the particular types of diseases, but also from lowered productivity measured with the ratio of real working time to nominal working time.

Higher cost of employment (lower productivity) is caused mainly by the legal provisions guaranteed to a disabled employee which include:

- working time shortened by 2 hours (5\%) per week for people with slighter type of disability,

- working time shortened by 2 hours (17\%) per week for people with heavy and moderate type of disability,

- additional break in work for 30 minutes daily in order to do some physical exercise or rest $(6 \%)$ for all disabled employees,

- additional holidays (10 days) for people with heavy and moderate type of disability,

- being exempt from providing employment but preserving the right to payment for the period of 21 days annually in order to participate in rehabilitation holidays for people with heavy and moderate type of disability,

- providing higher standard of working conditions (adapting sanitary rooms, abolishing architectural barriers, improper lightening). 
Table 1. Decrease in efficiency according to the type of disability (source: [1])

\begin{tabular}{|c|l|c|c|c|}
\hline No & \multicolumn{1}{|c|}{ Type of disability } & $\begin{array}{c}\text { Participation in } \\
\text { the population of } \\
\text { employees (\%) }\end{array}$ & $\begin{array}{c}\text { Decrease in } \\
\text { productivity } \\
(\%)\end{array}$ & $\begin{array}{c}\text { Measured } \\
\text { decrease in } \\
\text { productivity } \\
(\%)\end{array}$ \\
\hline 1 & Diseases of hearing and speech organs & 6 & 10 & 0,6 \\
\hline 2 & Mental and nervous diseases & 8 & 50 & 4,0 \\
\hline 3 & Mental handicap & 8 & 80 & 6,4 \\
\hline 4 & Diseases of sight organ & 9 & 30 & 2,7 \\
\hline 5 & Diseases of internal organs & 23 & 20 & 4,6 \\
\hline 6 & Diseases of limbs and spine & 25 & 30 & 7,5 \\
\hline 7 & Remaining and related diseases & 22 & 40 & 8,8 \\
\hline & Total number for the whole population of employees (as estimated) & 34,6 \\
\hline
\end{tabular}

\subsection{Scale and structure of the problem}

Data provided by GUS - Main Statistical Office showed that in 2002 there were more than 5457 thousands disabled people that is $10 \%$ of all the population of Poles, $84,5 \%$ of which do not have any chance for employment. The number of serious disabilities has also increased dramatically, for example annually there are about 1600 new cases of people who have to use a wheelchair on the permanent basis.

Impairments and limb diseases are the major or secondary cause of all identified causes of disability. According to Main Statistical Office in the first quarter of 2002 [14] it was discovered that disabled people with alternative abilities are $42 \%$ of all disabled population that is about 2,2 million people, who have only one type of disability. If we take into consideration the occurrence of different types of disabilities then the number of people with limb dysfunctions will increase to 1 million.

Alternative dysfunction can concern:

- alternative and manipulation limitations,
- using special and rehabilitation equipment,

- upper and lower artificial limbs,

- alternative limitations in the particular parts of the body,

- difficulties in moving on an even surface, staircase and ladder,

- limitation limiting kneeling and running,

- difficulties in moving on soft and uneven ground,

- difficulties in leaning,

- rheumatic deformations.

The structure and scope of the problems connected with alternative disabilities has been identified on the basis of the results of my own questionnaire carried out in 13 rehabilitation clinics in companies.

The results of the researches are illustrated in Fig. 1, 2, 3 and 4 and in Table 2.

Out of 96 disabled people included in the questionnaire, the researchers identified 20 cases of spinal impairments. The type and frequency of impairments is illustrated in Table 3. 


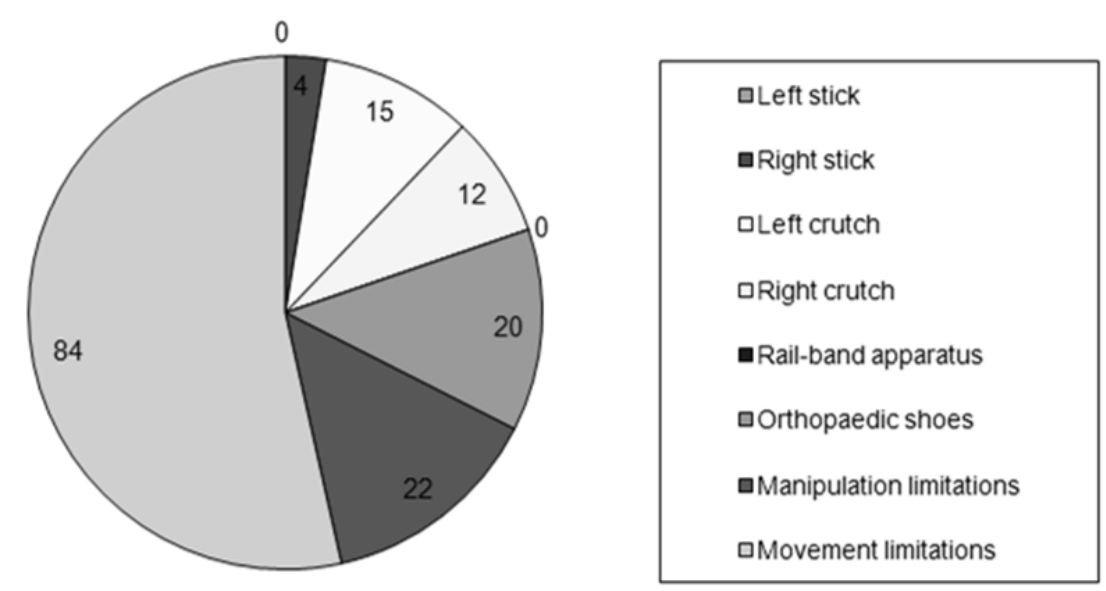

Figure 1. Special and rehabilitation equipment for people included in the research program

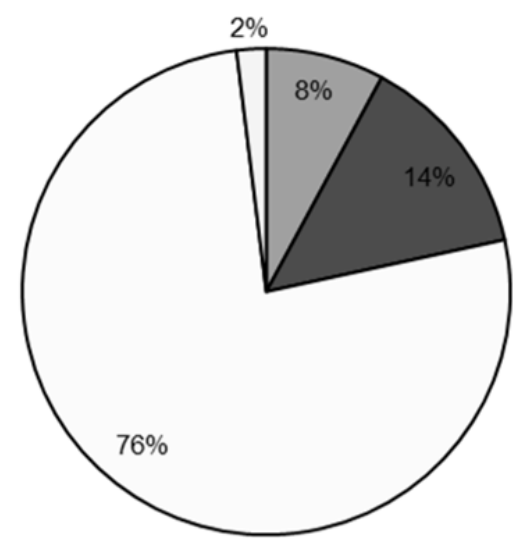

\begin{tabular}{|l|}
\hline 口Upper \\
םLower \\
םWithout artificial limbs \\
םUpper and lower \\
\hline
\end{tabular}

Figure 2. Percentage of people who have artificial upper and lower limbs

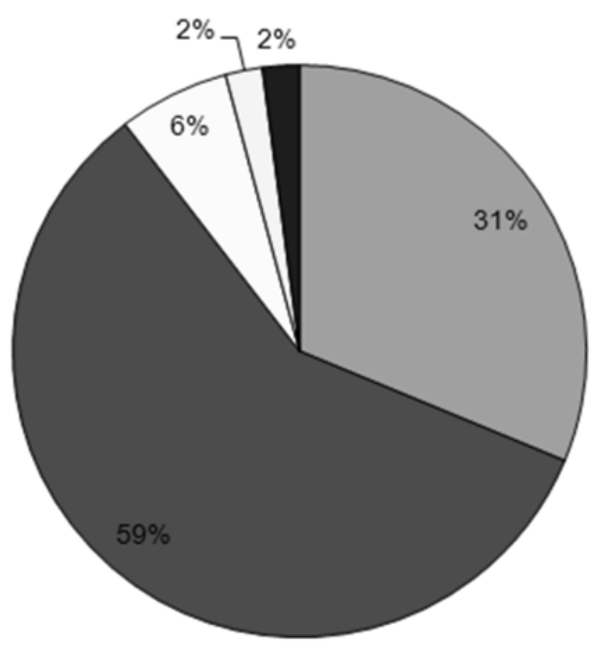

\begin{tabular}{|c|}
\hline ㅁack \\
\hline घStanding posture \\
\hline$\square$ Sitting posture \\
\hline 口Walking \\
\hline aLeaning \\
\hline
\end{tabular}

Figure 3. Limitation of movement ability in particular positions 


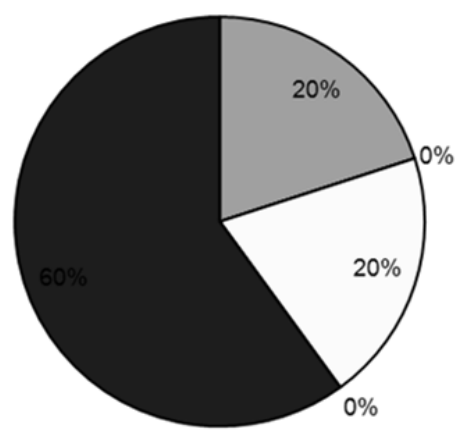

\begin{tabular}{|c|}
\hline 口Stiff hip-joint \\
\hline 口Rheumatoid hip-inflammation \\
\hline 口Stiffening inflammation of spinal joints \\
\hline 口Stiffening inflammation of hand joints \\
\hline Others \\
\hline
\end{tabular}

Figure 4. Occurrence of rheumatic deformations

Table 2. Percentage of physical ability among people included in the questionnaire researches

\begin{tabular}{|c|c|c|c|c|c|}
\hline \multirow[b]{2}{*}{ Disease type } & \multicolumn{5}{|c|}{ Percentage share $\%$} \\
\hline & $\begin{array}{c}\text { Complete } \\
\text { ability }\end{array}$ & $\begin{array}{c}\text { Small } \\
\text { difficulties }\end{array}$ & $\begin{array}{c}\text { Big } \\
\text { difficulties }\end{array}$ & $\begin{array}{l}\text { Practically } \\
\text { impossible }\end{array}$ & Impossible \\
\hline Limitations in moving on even surface & 20 & 58 & 20 & 0 & 2 \\
\hline Limitations in moving up/down the stairs & 8 & 42 & 48 & 2 & 2 \\
\hline $\begin{array}{l}\text { Percentage of people who cannot climb } \\
\text { up the ladder }\end{array}$ & 0 & 23 & 33 & 19 & 25 \\
\hline Limitations which unable kneeling & 7 & 24 & 43 & 13 & 13 \\
\hline Limitations which unable running & 2 & 12 & 40 & 15 & 31 \\
\hline Percentage of people who cannot run & 2 & 8 & 31 & 23 & 36 \\
\hline Limitations in moving on the soft ground & 4 & 27 & 55 & 7 & 7 \\
\hline $\begin{array}{l}\text { Limitations in moving on uneven } \\
\text { difficult ground }\end{array}$ & 4 & 29 & 44 & 13 & 10 \\
\hline Difficulties in leaning & 12 & 51 & 33 & 2 & 2 \\
\hline
\end{tabular}

Table 3. Types of spinal impairment

\begin{tabular}{|l|c|}
\hline \multicolumn{1}{|c|}{ Description } & $\begin{array}{c}\text { Frequency } \\
\text { of occurrence }\end{array}$ \\
\hline Limitation in mobility between vertebra on the neck, chest and loins-sacral section & 1 \\
\hline Th7-Th8 rupture of pultaceous core & 1 \\
\hline Post-accident damage of the loins section of the spine & 1 \\
\hline S' chest and loin curvature of the spine & 1 \\
\hline Impairment of the loins section of the spine - stiff and aching section & 1 \\
\hline Degenerative changes in the neck, chest and loins-sacral section of the spine & 1 \\
\hline Degenerative changes in the chest and loins-sacral spine & 2 \\
\hline Degenerative changes in the neck and chest spine & 2 \\
\hline Degenerative changes in the neck, chest and loin-sacral spine & 1 \\
\hline Degenerative changes in the neck and chest section of the spine & 1 \\
\hline Degenerative changes in the neck, chest and loins-sacral part of the spine & 1 \\
\hline Degenerative changes in all the spinal sections & 1 \\
\hline
\end{tabular}




\subsection{Complexity of the problem}

In order to establish correlation between the requirements of workstations and abilities of people with alternative abilities, it is necessary to take into consideration two groups of criteria:

- type of dysfunction,

- placement of dysfunction.

From the point of view of the type, dysfunctions can be divided into:

- loss of parts of the body and limbs, e.g. innate losses, amputations,

- dysfunctions of joints' kinesis, e.g. limitation of movements, switching off some degrees of autonomy, stiffness of joints (anykylosis, artrodesis),

- dysfunctions to dynamism of limbs, e.g. paresis and paralysis (flabby, spastic),

- complex dysfunctions (different combinations).

Depending on dysfunction placement in relation to reference system defined by fibular and transversal surface we can differentiate:

- symmetric movement dysfunctions in relation to fibular surface, e.g.: paresis or paralysis of both upper and lower limbs,

- asymmetric movement dysfunctions in relation to fibular surface, e.g.: paralysis on one side,

- symmetric movement dysfunctions in relation to transversal surface, e.g.: losses or paresis/limbs paralysis on the same height,

- asymmetric movement dysfunctions in relation to transversal surface, e.g.: similar dysfunctions on different heights.

What is more there are different possibilities in regard to movement and manipulation activities. Manipulation activities consist of elementary movements of upper limbs. Therefore it is necessary to learn the degree of ability for each of these movements which include: movements of fingers, movement of hand (palm and fingers), repetitive movements, turning and indirect movements of forearm, arm movements and arm movements together with shoulder collar. Evaluation includes also such manipulation activities as the ability of taking a grip, reaching, carrying, lifting, putting down, pushing, attracting, spinning, dismantling and squeezing. The indicators of physical ability are also important: adequacy, precision, speed, skillfulness, strength and coordination of movements.
Movement activities are connected with moving the body with the use of the lower limbs. Therefore it is important to learn the degree of ability in such activities as walking on an even surface, walking up and down the stairs, walking up the ladder, kneeling, running, jumping, walking on the soft and uneven ground and leaning.

Table 4. Changes occurring in upper limbs

\begin{tabular}{|c|c|}
\hline Type of dysfunction & Area \\
\hline Fingers missing & $\begin{array}{l}\text { - } \text { thumb } \\
\text { - } \text { pointing } \\
\text { - } \text { middle } \\
\text { - } \text { annular } \\
\text { - } \text { small } \\
\text { - } \text { none }\end{array}$ \\
\hline $\begin{array}{l}\text { Impairments visible in } \\
\text { stiffened joints or } \\
\text { movement limitation, } \\
\text { within }\end{array}$ & $\begin{array}{ll} & \text { thumb } \\
\text { - } & \text { pointing } \\
\text { - } & \text { middle } \\
- & \text { annular } \\
- & \text { small }\end{array}$ \\
\hline $\begin{array}{l}\text { Impairments of the } \\
\text { wrist }\end{array}$ & $\begin{array}{l}\text { - } \text { below the joint } \\
\text { - } \text { above the joint } \\
\text { - immobility of the joint } \\
\text { visible in the stiffness or } \\
\text { movement limitation }\end{array}$ \\
\hline $\begin{array}{l}\text { Impairments of the } \\
\text { elbow joint }\end{array}$ & $\begin{array}{l}\text { - } \text { below the joint } \\
\text { - } \text { above the joint } \\
\text { - immobility of the joint } \\
\text { visible in the stiffness or } \\
\text { movement limitation }\end{array}$ \\
\hline $\begin{array}{l}\text { Impairments of the } \\
\text { shoulder joint }\end{array}$ & $\begin{array}{l}\text { - } \text { below the joint } \\
\text { - } \text { above the joint } \\
\text { - immobility of the joint } \\
\text { visible in the stiffness or } \\
\text { movement limitation }\end{array}$ \\
\hline $\begin{array}{l}\text { Too short limb, if the } \\
\text { shortening concerns }\end{array}$ & $\begin{array}{l}\text { - } \text { proportionally, the whole } \\
\text { limb } \\
\text { - } \text { section of the limb }\end{array}$ \\
\hline $\begin{array}{l}\text { Too long limb, if the } \\
\text { lengthening concerns }\end{array}$ & $\begin{array}{l}\text { - } \text { proportionally the whole } \\
\text { limb } \\
\text { - } \text { section of the limb }\end{array}$ \\
\hline
\end{tabular}

Alternative dysfunction can be a result of:

- dysfunction of upper limbs (not resulting from spinal damage),

- dysfunction of lower limbs (not resulting from spinal damage),

- deformation as a result of rheumatic diseases,

- dysfunction of limb caused by spinal damage. 
Dysfunction of upper limbs refers to the left or right hand. In both cases there can appear changes presented in Table 4.

The performed analysis shows a great variety of dysfunctions of human alternative system. Even identical diagnosis in few persons gives different possibilities of action. Specially when we consider partial disability and paralysis. Within the same formal diagnosis e.g. „limb disability” there can be great differences in ability of a given limb in different people. Therefore every design of workstation for a disabled person should be based on a detailed individual analysis and functional diagnosis.

\section{$5 \quad$ Results}

Data collected in the questionnaires served to elaborate a method of designing workstations with limb dysfunctions and its computer implementation. Among many areas which require analysis, the issue of spatial planning of a workstation in accordance with the needs and abilities of disabled people with limb impairment, was taken into focus. The scope of using the method was limited to alternative dysfunctions as the biggest and at the same time the most complex area of functional disturbances in the human alternative system.

\subsection{Workstation design procedure}

It was assumed that designing workstations will take place at the following stages:

I stage concerns modeling the body shape of the workstation's user and requires building:

- model of database including information on anthropometrical parameters of model forms,

- model of database of diseases and deformations according to medical documentation,

- model of knowledge base enabling translation of „medical base” into the parameters required by the base of models parameters,

- interface: parameters base - Anthropos.

II stage concerns building a model of a workstation in accordance with the identified modules.
III stage concerns examining the relation between the disabled person's alternative possibilities and space in which he/she is to function.

The diagram of the workstation designing method has been presented in Fig. 5.

In order to elaborate the method two questionnaires were drawn up:

- questionnaire of a disabled person's body shape with an alternative dysfunction,

- questionnaire of requirements posed by a workstation.

A tool which aids the researches in the project is Anthropos, a computer program working in Auto$\mathrm{CAD}$ environment. What is more a proper consulting system has been elaborated which aids decision making process concerning selection of workstation for an individual user.

One of the elements of the method is a visualization of the process of adapting an employee to a workstation with the help of Anthropos packet. This packet is a tool which will help visualization provided that the basic objects - human and workstation - have been well defined in three dimensional way. A human has been well described with the help of a questionnaire including data on the employee's dysfunctions. It is true that the geometry of all the elements was not precisely described in the questionnaire, but it was possible to use the base of anthropometrical features of a population, included in Anthropos packet.

The elaborated method of workstation designing enables to:

- select workstation suitable for a given type of dysfunction according to the needs of people looking for a job,

- find among disabled people those who can work at the workstation endowed with definite parameters,

- define adaptation activities for a workstation so that it is possible to employ a disabled employee.

In all these cases we define the priority: human can work only at such a workstation where basic use and ergonomic parameters meet the requirements of a potential employee. This is a basic criterion of selecting workstations for people and people for workstations. 


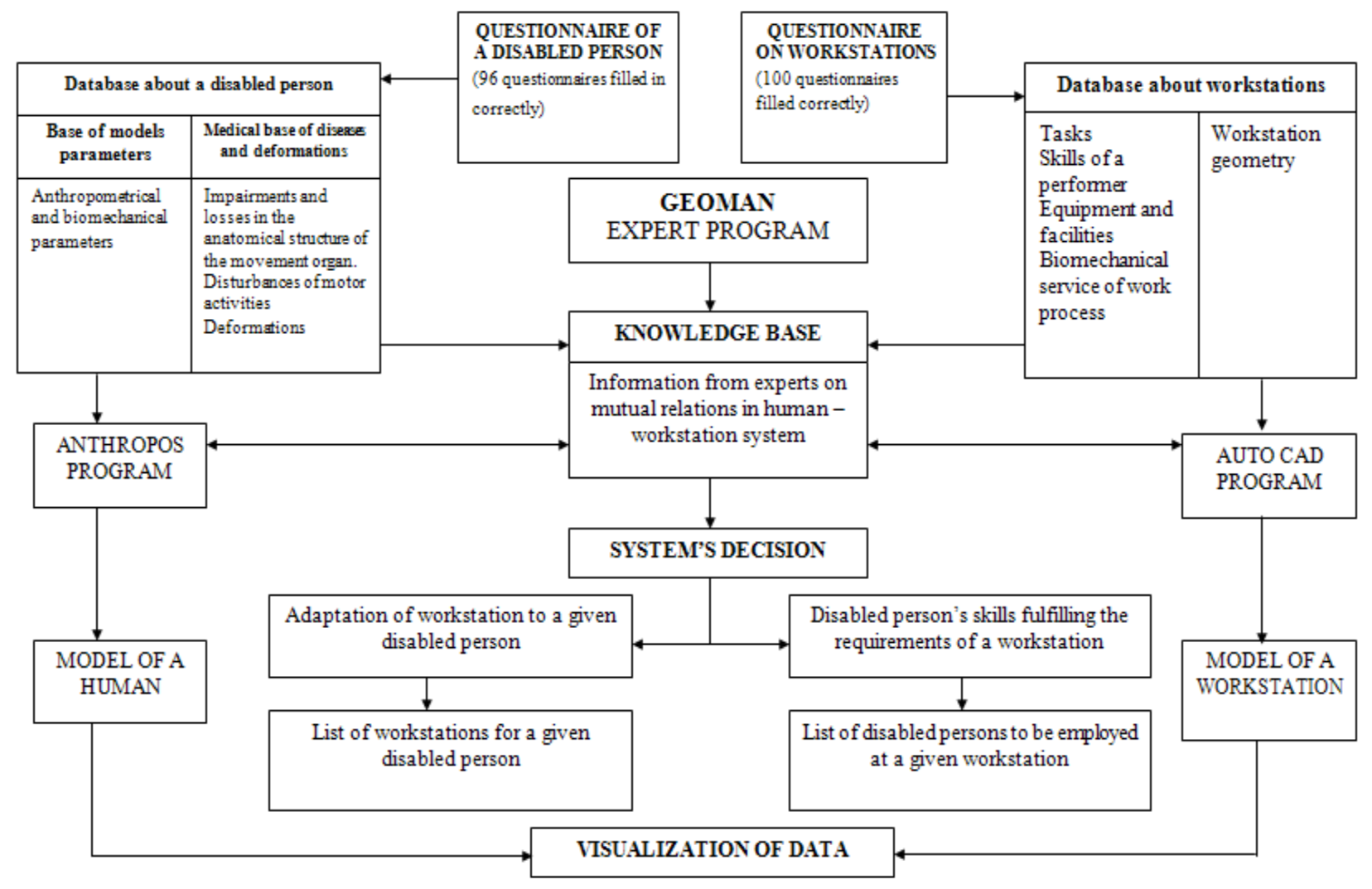

Figure 5. Diagram representing the method of a module designing of workstations for disabled persons (source: [4])

The system in the first case will search a database with data on workstations for such workstations whose use parameters are beyond the minimal requirements of a disabled person.

In the second case working of the system is similar and actually operated in the same way but due to the efficiency of database, the system will search a base of individuals looking for persons whose requirements are lower than those at the analyzed workstation. In both cases it is human with his dysfunction that plays the main role.

\subsection{Computer implementation of workstation designing method for disabled people}

The main aim of creating computer system of workstation designing method for disabled people is the possibility of stimulating the interaction of the elements of the system: human - workstation. Examining the above relations requires building the model of a generalized body shape of a disabled per- son who has some definite dysfunctions and a workstation model in which the disabled person is to function. Thus it was decided that the designed system should enable to:

- collect information on disabilities among certain population,

- collect information on working environment where people with alternative abilities could be possibly employed,

- search both databases in order to find functional correspondences in the other database; the search can be carried out using equivocal criteria; functioning of such tool enables finding for example not concrete and ready workstations for people with alternative abilities but a group of workstations together with a list of their possible modifications; the role of decision-maker consists in establishing which of the changes proposed by the system are to be actually realized,

- indicate proper matches at a workstation in order to employ adequate people with alternative abilities at a given workstation, 
- suggest possible modification of a workstation in a given range so that modifications could meet the requirements of an employed person.

For the sake of the method a model of database including information on anthropometical parameters of modeled forms, given diseases and deformations according to medical documentation was elaborated. What is more a model of knowledge base which enables translation of ,medical base" into the parameters required by the base of models parameters was also elaborated. The interface consisted in Anthropos, the base of parameters.

Particular efficiency of the presented attitude consists in creating a set of recommendations about reconfigurations of workstation's geometry in order to adapt to a given case of a disabled person with dysfunctions.
The designed system should serve to:

- select a workstation with a suitable parameters and advantages for a given type of dysfunctions characteristic for people looking for a job,

- find among disabled people those who can work at a workstation endowed with specific parameters.

In both cases we set the priorities: a human can only work at such a workstation where basic use and ergonomic parameters meet the requirements (mainly health requirements) of a potential employee. It is a basic criterion of selecting workstations for people and people for workstations.

The system in the first case will search workstations database for such workstations whose use parameters are beyond the minimal requirements of a disabled person.

\section{INPUT}

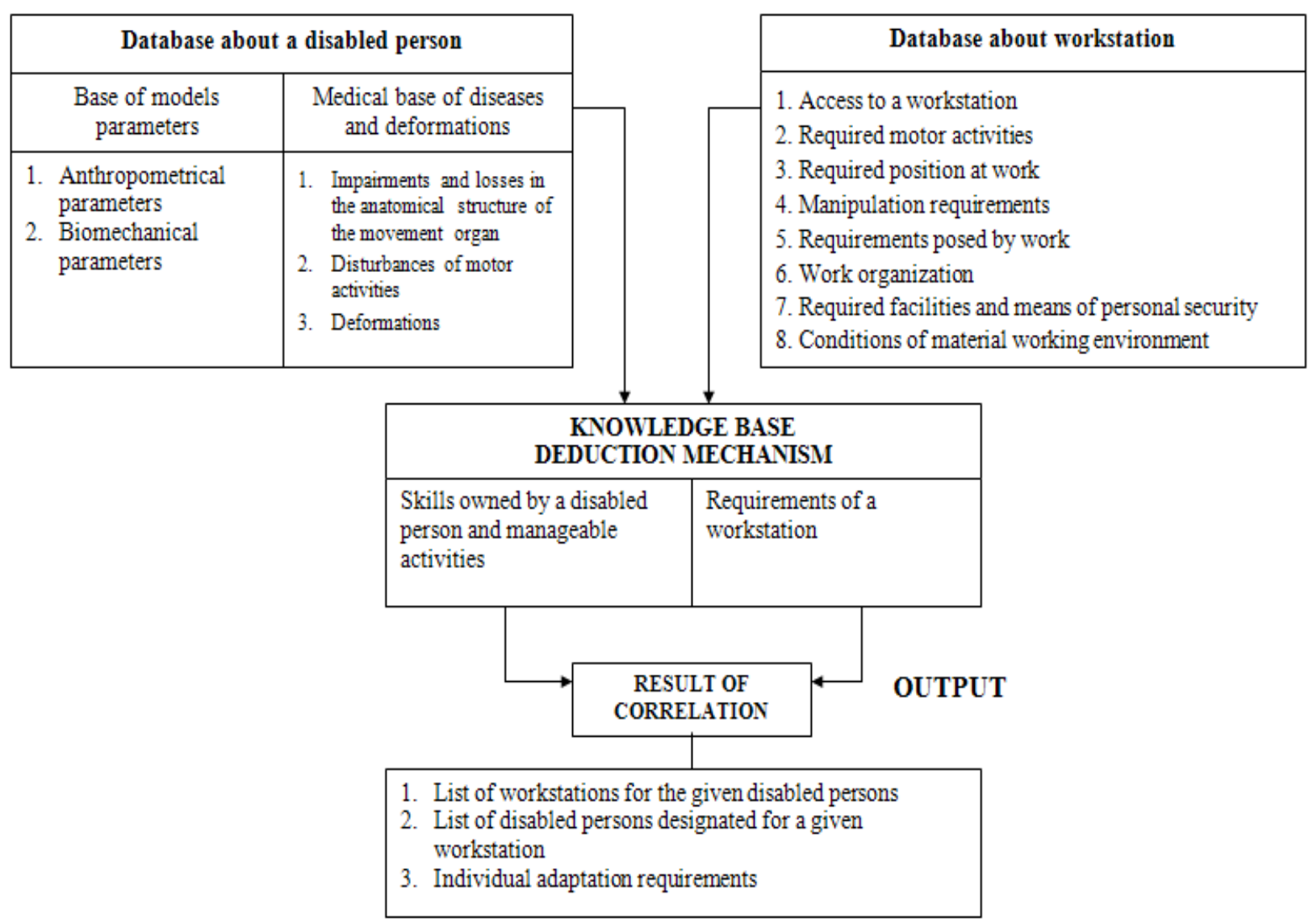

Figure 6. Functional model of computer system workstation designing for disabled persons (source: [4]) 
In the second case working of the system is similar and run almost in the same way but due to the efficiency of database, the system will search a base of individuals whose requirements are lower than present at the analyzed workstation. In both cases a human with his dysfunctions plays the main role. The essence of the computer system is presented in Fig. 6.

The example of selected windows from a computer program aiding the method of designing workstations for disabled people id represented in Fig. 7 and 8. The window presented in Fig. 7 is the first interface dialogue window of the user of the external database application. We have here a possibility of drawing up a description of particular alternative limitations and choosing the areas of occurrence of limb dysfunctions.

Next dialogue window (Fig. 8) allows introducing additional data not included in direct dysfunctions. Introducing detailed data about disabled people's dysfunctions enables the next third dialogue window etc.

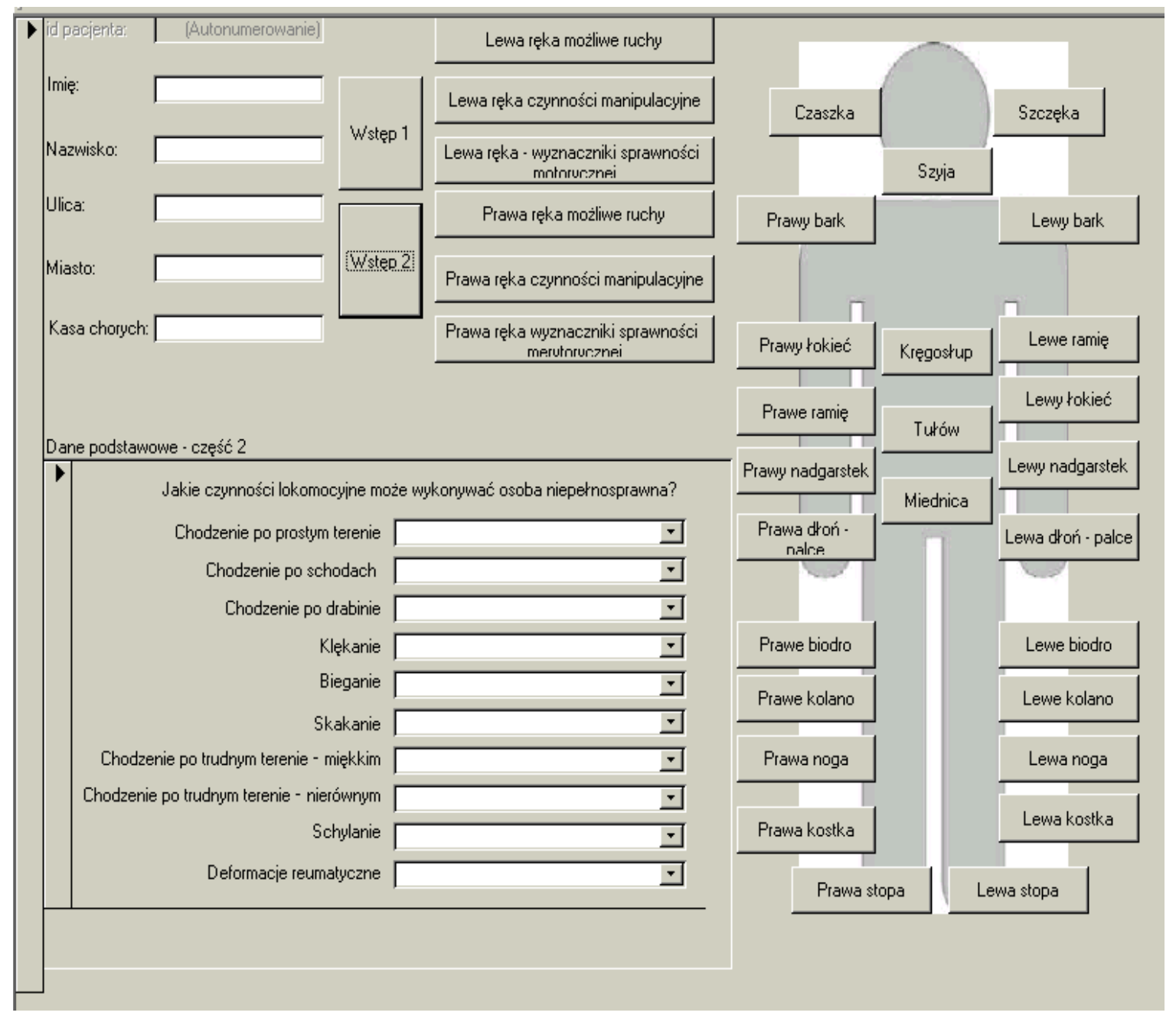

Figure 7. Window of a base to fill in the description of the individual dysfunctions (source: [4]) 


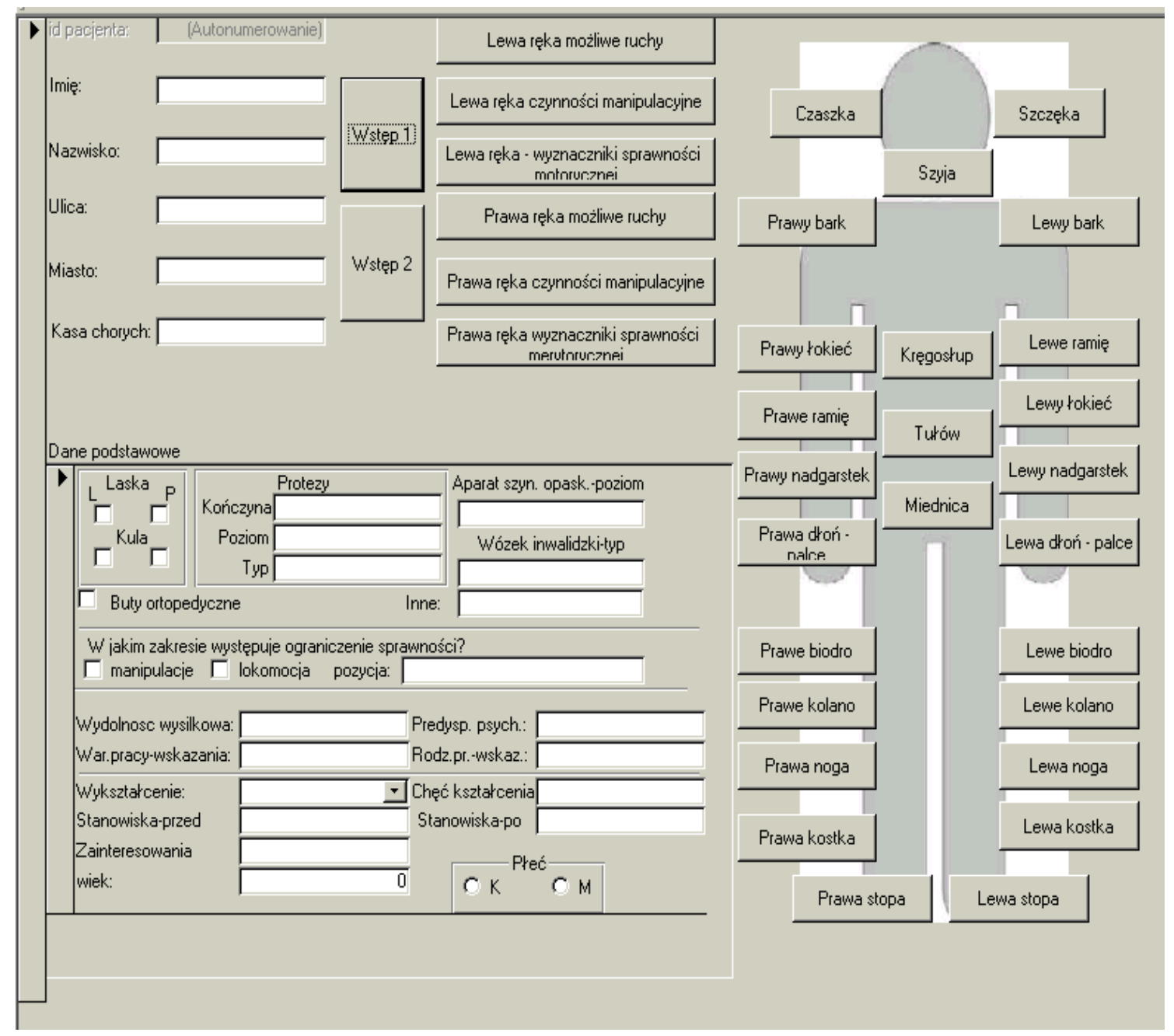

Figure 8 . Window to introduce additional data - besides direct dysfunctions (source: [4])

\section{6}

\section{Application}

Implementation of the workstation designing method for disabled people was started at S.I. ELERMET Company at the Electromechanical department in Biała Podlaska.

ELERMET, the Co-operative of Disabled People runs its own production activity at the following departments:

- wear (protection and working wear, wear for health service, uniforms and special wear),

- electro-technical (contractional tubes and conductors, installation collets, ampere currant gauges, stabilizers for sodium, mercury and halogen lamps),

- artificial materials (products of artificial materials and furniture, containers from artificial materials made for LUBLIN cars, produced with the use of a special modern technology - the method of gust, retarding reservoirs for the car radiator systems).

The Co-operative has its own commercial network (a warehouse, 8 shops), it runs its own investment and renovation business. It also has rehabilitation clinic. ELREMET Co-operative of Disabled People employs 597 people 306 of whom are disabled people which is $51,3 \%$ of the staff. There are 36 disabled people employed at the electromechanical department. The conclusions of the interview, provided by 20 people with different disability group, reveal that $35 \%$ of the researched employees notice barriers at their workstations. These disturbances are brought about by a wrong selection of gauges, improper seat, too small working space. Most of the employees complained about the heavy load on hand muscles and mental 
overload with the performed work. The overload on the upper limbs, which unfortunately appears very often, has a very bad effect on mental well being and of course on work efficiency.

Good economic condition of the Co-operative helps create new jobs with a special consideration of workstation for disabled people. General working conditions are already adapted to the needs of disabled people. The company has such facilities as lifts, special banisters, vehicles which enable wheelchairs to move around. However workstations need modernizing.

\subsection{Registration of data for designing purposes}

A register of diseases and workstations was started in the company in the form of catalogues. A list of diseases which occur in 36 employees working at the electro-technical department was drawn up. The register lists disabilities, disability group, classification to one of 7 areas of disability and comments on special recommendations or indications. The evaluation of disability was settled on the basis of health card and medical commission's opinion. The fragment of the register is presented in Table 5 .

A catalogue of typical workstations was elaborated for the Electro-technical Department. The catalogue lists workstations at which disabled people may be employed. Since people with different dysfunctions can work at these workstations, the catalogue indicates for each workstation the chances of employment for people with specific diseases classified into disability areas. The register of typical workstations including possible diseases, which can occur in the disabled employees, is presented in Table 6 .

\subsection{Designing a workstation to prepare the base of a stabilizer}

The procedure of ergonomic designing was conducted in accordance with the elaborated method. On the basis of the collected data about a disabled person and workstation for preparing the base of a stabilizer a simulation of design solutions was performed. According to the obtained results an action was launched aimed at improving working conditions at the workstation. The effects of improvement were presented in the human - technical object - environment system, including specific features of an employed worker. These features include:
A. features of a disabled person,
B. workstation equipment,
C. spatial structure,
D. work methods,
E. work organization,
F. material work environment.

Table 5. Catalogue of diseases of the persons employed at the electro-technical department (fragment)

\begin{tabular}{|c|l|c|c|c|c|c|}
\hline \multirow{2}{*}{ No. } & \multicolumn{1}{|c|}{ Type of disease } & \multicolumn{2}{|c|}{ Sex } & & \multicolumn{2}{c|}{ Comments } \\
\cline { 3 - 7 } & me- & Male & $\begin{array}{l}\text { Disability } \\
\text { group }\end{array}$ & Disability area & $\begin{array}{l}\text { C - contraindication } \\
\text { R - special recommendation }\end{array}$ \\
\hline 1 & Spastic paralysis of the left leg & & $\mathrm{X}$ & III & Limb defect & $\begin{array}{l}\text { C - hard physical work } \\
\text { requiring a lot of walking }\end{array}$ \\
\hline 2 & $\begin{array}{l}\text { Spastic paralysis of the upper right } \\
\text { limb }\end{array}$ & & $\mathrm{X}$ & II & $\begin{array}{l}\text { Movement disa- } \\
\text { bility }\end{array}$ & $\begin{array}{l}\text { C - work requiring both } \\
\text { hands }\end{array}$ \\
\hline 3 & $\begin{array}{l}\text { A deaf-mute person, paresis of hip- } \\
\text { joint, shortening of lower limbs }\end{array}$ & & X & II & $\begin{array}{l}\text { Defect of speech, } \\
\text { hearing, limbs }\end{array}$ & $\begin{array}{l}\text { C - hard work requiring } \\
\text { speaking and walking, } \\
\text { R - work in a sitting posture }\end{array}$ \\
\hline 4 & $\begin{array}{l}\text { Loins and sacral curvature of the } \\
\text { spine }\end{array}$ & & X & II & Spine defect & R - work in a sitting posture \\
\hline 5 & $\begin{array}{l}\text { Spastic paresis of lower limbs, } \\
\text { paresis of the upper right limb, } \\
\text { mental deficiency of the small } \\
\text { degree, astigmatism }\end{array}$ & & X & I & $\begin{array}{l}\text { Complex disabil- } \\
\text { ity }\end{array}$ & $\begin{array}{l}\text { R - easy and simple work to } \\
\text { perform }\end{array}$ \\
\hline
\end{tabular}


Table 6. Catalogue of typical workstations at the Electro-technical Department

\begin{tabular}{|c|c|c|c|c|c|c|c|c|c|}
\hline \multirow[b]{2}{*}{$\dot{0}$} & \multirow[b]{2}{*}{ 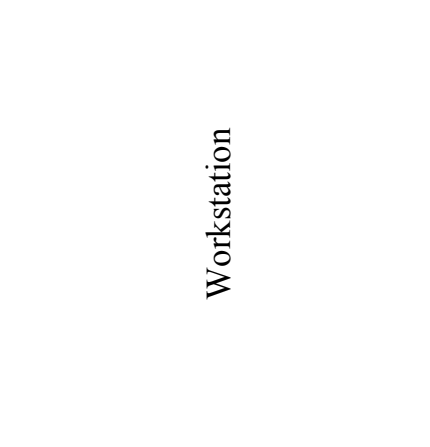 } & \multirow[b]{2}{*}{ 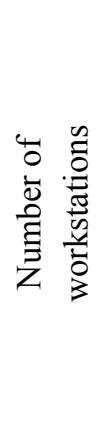 } & \multicolumn{7}{|c|}{$\begin{array}{l}\text { Possibility of employing disabled people according to disabil- } \\
\text { ity areas }\end{array}$} \\
\hline & & & 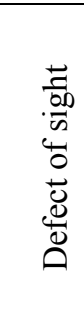 & 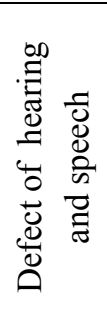 & 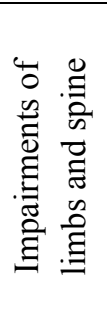 & 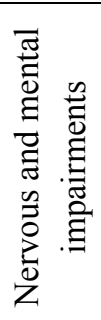 & 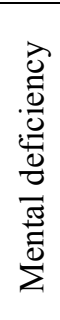 & 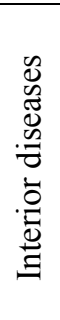 & 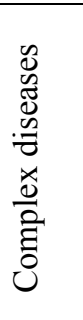 \\
\hline 1 & Insulation winder & 9 & $\mathrm{X}$ & $\mathrm{X}$ & $\mathrm{X}$ & & & $\mathrm{X}$ & $\mathrm{X}$ \\
\hline 2 & $\begin{array}{l}\text { Workstation for control } \\
\text { measurements }\end{array}$ & 2 & $X$ & & $X$ & & & & \\
\hline 3 & $\begin{array}{l}\text { Workstation for preparing the } \\
\text { base of the stabilizer }\end{array}$ & 3 & $X$ & & & $X$ & & & \\
\hline 4 & $\begin{array}{l}\text { Workstation for installing } \\
\text { moulders }\end{array}$ & 3 & & $X$ & & & & & $\mathrm{X}$ \\
\hline 5 & $\begin{array}{l}\text { Workstation for designing } \\
\text { the stabilizer }\end{array}$ & 10 & $X$ & $X$ & $X$ & $X$ & $X$ & $\mathrm{X}$ & $\mathrm{X}$ \\
\hline 6 & $\begin{array}{l}\text { Workstation for installing the } \\
\text { amperometer }\end{array}$ & 2 & $X$ & & $X$ & & & & \\
\hline
\end{tabular}

\section{A. Features of a disabled person}

Sex: Male.

Age: 36 years.

Employment practice: 15 years.

Disability group: I.

Description of disability: spastic paresis of limbs, paresis of upper right limb, mental deficiency of the small degree, astigmatism.

Recommendations: No work or work only in the company of work protection in special conditions. Work, which is simple and easy to perform.

Anthropometrical data: while defining data the features differences resulting from disability were included:

- body height in a sitting posture

$1700 \mathrm{~mm}$

- sight surface height in a sitting posture

$1227 \mathrm{~mm}$

- shoulder height in a sitting posture

$1051 \mathrm{~mm}$

- elbow height in a sitting posture from the floor

- under-knee height
- maximal thigh girth

$139 \mathrm{~mm}$

- thigh sedentary length

- length of a seat

- height of a seat

- reach of the left limb
$457 \mathrm{~mm}$

$400 \mathrm{~mm}$

$445 \mathrm{~mm}$

$752 \mathrm{~mm}$

A task for realization: preparing moulders for the installation of the stabilizer.

Character of the activities performed: manual work, manipulation - sight work.

Employee's tasks: taking $\mathrm{C}$ and $\mathrm{T}$ moulders, putting them properly, putting them into strickle and examining a given type of a stabilizer.

\section{B. Workstation equipment}

Tools: a hammer, strickle board.

Table: adapted to the people with lower limbs paresis, it has a listed board which prevents small elements and tools from falling, on the left side of the table there is a tool box as the right hand is disable.

Seat: a chair for people with a limited ability of sitting down and getting up, endowed with side arms and mobile leaning seat with an option of autonomous sitting down and getting up which while sitting down turns to the vertical position and while getting up 
a special mechanism pushes the seat out together with a person (see Fig. 10).

\section{Workstation spatial structure}

The measurements of a workstation and equipment were selected in accordance with the anthropometrical data. While defining the measurements the differences of somatic features resulting from disability were taken into consideration. The manipulation height and comfort areas for legs in a sitting posture are presented in Fig. 9. The measurements of workstation Fig. 10. A surface which covered by a workstation: 6 square meters and 2 square meters not taken by an employee.

\section{Work methods}

Description of activities: basic activities performed by the left hand.

Tasks for the left hand:

- taking a moulder,

- putting in the right position,

- putting in the strickle,

- nailing with a hammer,

- winding with a tape.

Tasks for the right hand:

Due to a paresis there are only simple activities performed connected with holding

Work place: optional.

Labor effort: medium.

\section{E. Work organization}

A type of work performed: an employee at the workstation performs simple activities connected with packing moulders of type $\mathrm{T}$ and $\mathrm{C}$ with the help of simple tools: hammer, strickle, moulders.

Work efficiency: efficiency during a labor day is about 20-25 units/7 hours, efficiency per hour is about 3-4 units/1 hour.

Physical load: medium.

Working time: 7 hours.

Number of breaks: 4 . Total time for rest is about 40 minutes.

Time of breaks: first break - 15 minutes, second break - 10 minutes, third break - 10 minutes, fourth break -5 minutes.

First break for corrective exercise should take place in a scheduled time. It should influence general health condition, improve fitness of limbs which have paresis and relax the hand which performs almost all ativities.

The remaining breaks can be regulated optionally depending on the mental and physical well being.

The rule of individualization for work organization: due to the paresis of lower limbs and upper right hand, an employee is provided with material to work and the receipt of ready packets.

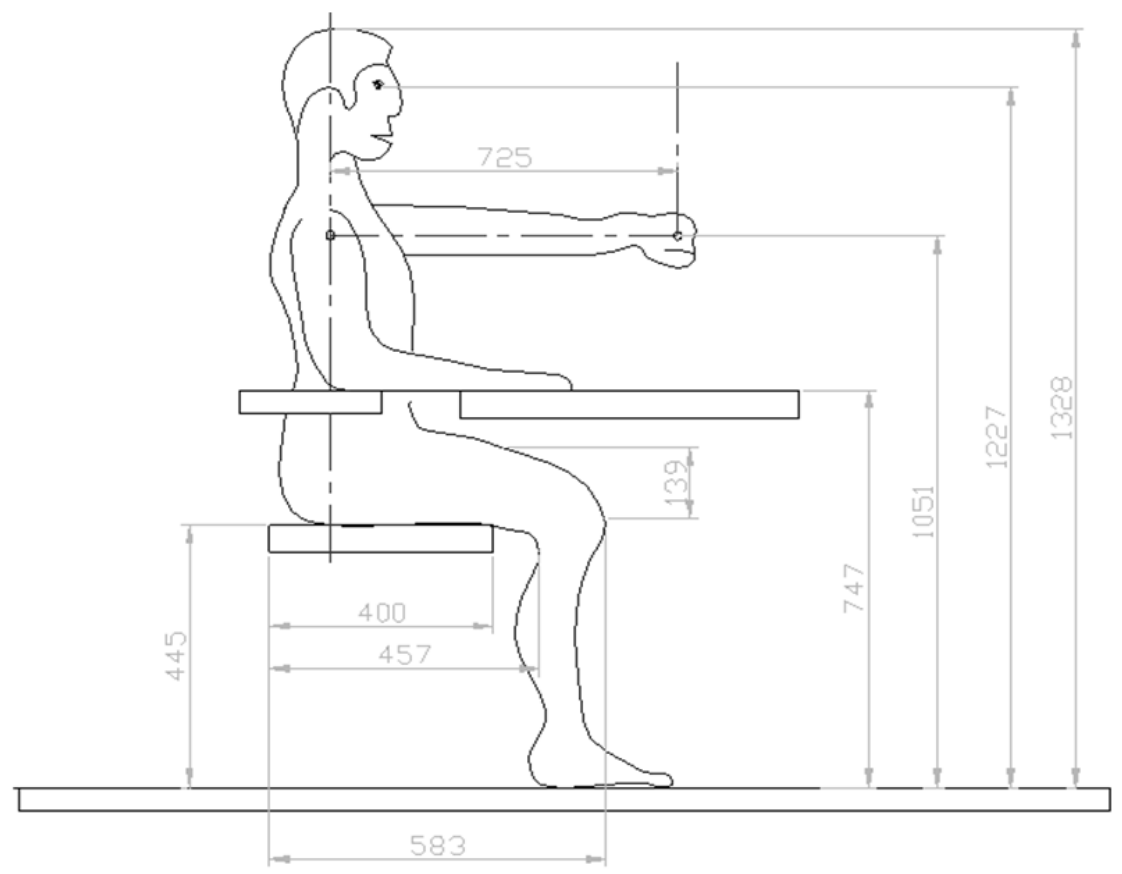

Figure 9. Defining manipulation height and comfort area for legs in a sitting posture 


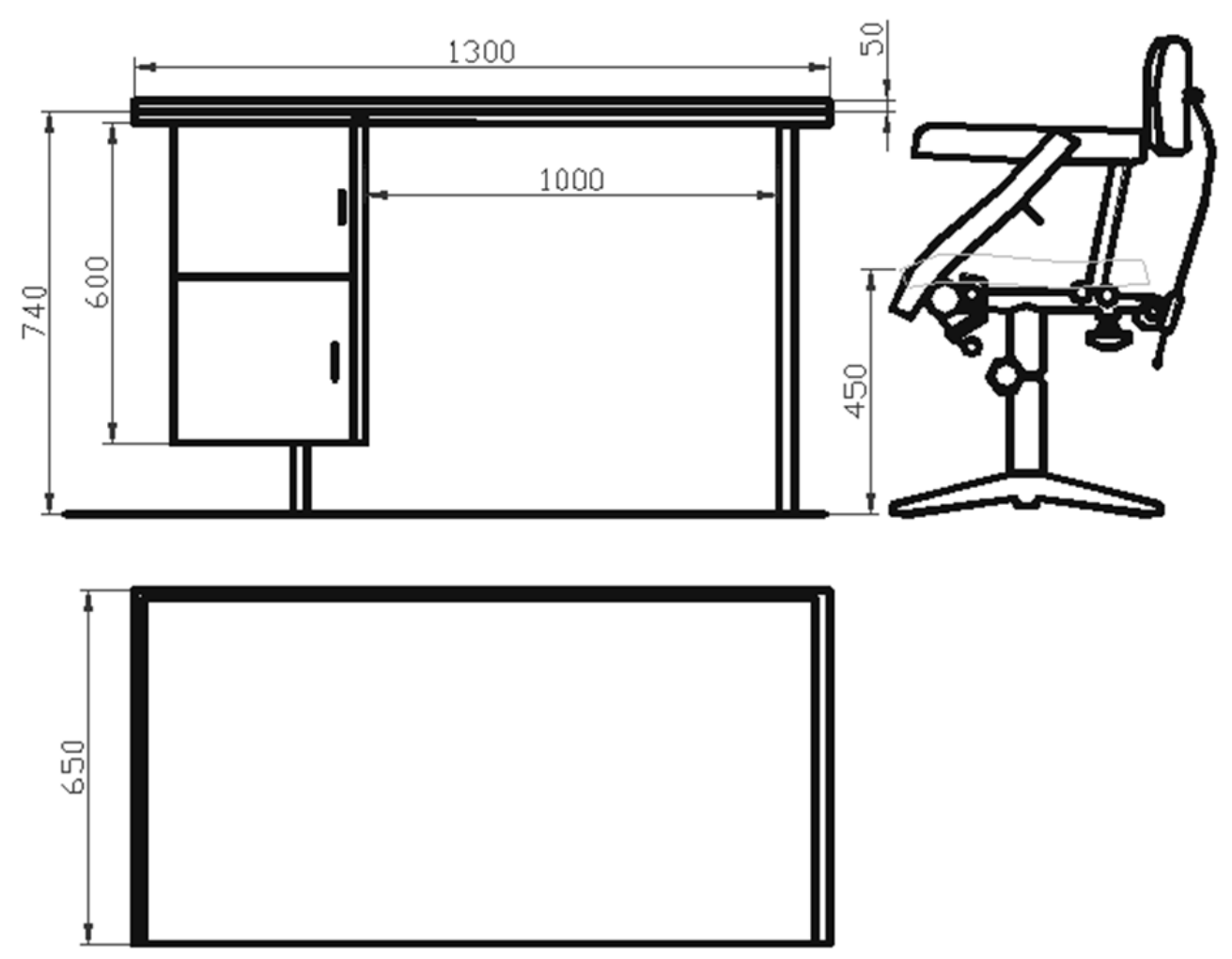

Figure 10. Defining workstation measurements to prepare the base of a stabilizer

\section{F. Material work environment}

Temperature: $23 \mathrm{C}$.

Noise: max. $72 \mathrm{~dB}$.

Light: $3001 \mathrm{x}$.

\section{Conclusions}

The elaborated method and a computer program adapted to it will be verified in the companies of work protection and after gaining satisfactory results, they will be implemented into the normal practice of a company.

It is predicted that shaping working conditions at the workstation according to the mental and physical needs of disabled people will help overcome social barriers.

We hope that the suggested method will create equal chances for disabled people and help them function in the society as fully valuable members. What is more the efficiency of the company will increase dramatically as a result of disabled people's work.

\section{$8 \quad$ References}

[1] Barczyński A. - Companies of Work Protection in the Polish System of Professional Rehabilitation of Disabled People. KIG-R, Warszawa 2001.

[2] Barczyński A. - Cost of employment of people with alternative abilities. KIG-R, Warszawa 2008.

[3] Economic Activity of Poland's People I quarter 2007. Main Statistical Office, Warsaw 2007.

[4] Górska E. (ed.) - Projektowanie stanowisk pracy dla osób niepetnosprawnych. OWPW, wyd. II, Warszawa 2007.

[5] Górska E. - Analysis of Work Tasks for Recruiting Employees with Limb Impairment, Systems [in] Social and Internationalization Design Aspects of Human - Computer Interaction (Smith M.J., Salvendy G. ed.), Lawrence Erlbaum Associates Publishers, Mahwah-London 2001, pp. 405-409.

[6] Heath Condition and Needs of Disabled People in Poland in 2002. Main Statistical Office, Warsaw 2003. 
[7] International Classification of Impairments, Activities and Participation. A Manual of Disablement and Functioning. BETA-1 DRAFT FOR FIELD TRIALS. World Health Organization, Geneva 1997.

[8] Kaplan S.N., Mitchell M.L., Wruck K.H. - Clinical Exploration of Value Creation and Destruction in Acquisitions: Organizational Design, Incentives and Internal Capital Markets. Center for Research In Security Prices No. 450, p. 5, Graduate School of Business, University of Chicago 2000.

[9] Majewski T. - Type of disability in relation to the need of professional activation of disabled people [in] conference materials: Needs of professional activation of people with alternative abilities. KIG-R conference, Warszawa 30 May 2007.

[10] Majewski T. - How to employ people with alternative abilities. Guide for the employer. KIG-R, Warszawa 2007.

[11] Misztal M. - New supporting regulations for employers hiring people with alternative abilities in protected and open employment market. Info Baza, September 2007.

[12] Nevala-Puranen N., Louhevaara V., Itäkannas E., Alaranta H. - ERGODIS: A Method for Evaluating Ergonomics of Workplaces for Employees with Physical Disabilities [in] Proceedings of ERGON'AXIA 2000, Warsaw 2000, pp. 237239.

[13] Nevala-Puranen N., Seuri M., Simola A., Elo J. Physically Disabled at Work: Need for Ergonomic Interventions [in] Journal of Occupational Rehabilitation. Vol. 9, No. 4, 1999, pp. 215-225.

[14] National Labor Inspectorate report from 2007.

[15] Tortosa 1., Ferreras A., Garcia-Molina C., Diez R., Lazaro A., Cerezo C., Page A. - ErgoworkIBV: Method for Ergonomic Adaptation of Workplace for Disabled People [in] Proceedings of CAES'99 International Conference on Computer-Aided Ergonomics and Safety. Barcelona 1999.

[16] Välima M., Mikkonen P., Kantolahti T., Palukka P., Mattila M., Rautjärvi L., Kivi P. - The Model for Analysis of Work Ability at SMEs [in] Proceeding of the International Conference on Computer Aided Ergonomics and Safety CAES'99. Barcelona 1999.

[17] Välima M., Mikkonen P., Kantolahti T., Palukka P., Mattila M., Rautjärvi L., Kivi P. - How to Analyze Work Ability in Order to Promote It? [in] Proceeding of the $1^{\text {st }}$ International Conference on Occupational Risk Prevention ORP'2000. Tenerife, Spain 2000. 